\title{
Tourism and high speed rail in Spain: does the AVE increase local visitors?
}

April 25th, 2017

\begin{abstract}
This paper analyses from an empirical point of view the relationship between the provision of high-speed rail services (HSR) and the evolution of tourism at the local level in Spain. We have built a database of 124 municipalities during the 2005-2012 period to study the effects of the introduction of new HSR corridors on the number of visitors and their total and average stay at several end-line and intermediate cities as compared to similar counterparts not having such an infrastructure. We combine both difference-in-difference and panel data techniques to find that these effects are, in general, extremely weak or just restricted to larger cities, once other determining factors are controlled for.
\end{abstract}

Keywords: high speed rail, local tourism, difference in difference, panel data.

JEL codes: R42, R53, L83. 


\section{Introduction}

Amongst the multiple determinants of the attractiveness of a particular location from the point of view of tourism, accessibility usually ranks between the first two or three positions. A beautiful landscape, a historical monument or a sunny and fine sandy beach hardly becomes a successful tourist destination if transport infrastructure does not allow a convenient, comfortable and safe way to get there and return. At the local level, the endowment of roads, or the existence of rail and bus stations nearby - not to mention - an airport, makes a significant difference in the number of visitors that a city or a municipality receives each year (Leiper, 1990).

This issue is particularly relevant for Spain, a country that shares the feature of being a world's favourite tourist destination and the fact of having Europe's largest high-speed rail network (second in the world only after China). According to UNWTO (2015), nearly 65 million visitors arrived into Spain in 2014, contributing with more than $€ 64$ billion to the country's GDP (6.5\% of total). Most visitors came from the United Kingdom, France, Germany and Scandinavia, and - although $80 \%$ of them arrived by air - road and domestic rail transport also played a significant role in facilitating their movements from airports to final or transit destinations (FRONTUR, 2015) and short excursions to surrounding areas. In fact, the road network density in Spain (in terms of motorway $\mathrm{km}$ per $\mathrm{km}^{2}$ of land area) is well above the EU-28 average, and the country has spent over the last 25 years nearly $€ 50$ billion in developing a relatively dense HSR network connecting more than 80 large and medium-size cities.

From a technical point of view, the Spanish HSR (known as AVE, Alta Velocidad Española) is widely regarded as a success, since it has served to improve the service standards and the technical quality of infrastructure and rolling stock. Politicians also argue that it has progressively prompted a social and territorial cohesion effect, by reducing the generalized costs of travelling from/to the centre (Madrid) to the periphery (coastal provinces). However, several economists and academics have long questioned the opportunity costs of many HSR developments, particularly in very low demand routes where the induced effects were also weak or non-existent at all. Although the criticisms started with the initial projects, this literature has been largely ignored by mainstream HSR supporters (as argued, for example, in de Rus and Inglada, 1993, 1997; de Rus and Nombela, 2007; de Rus, 2011, or, more recently, in Betancor and Llobet, 2015). The international experience also doubts of political interference on high-speed projects, as suggested by Albalate and Bel (2012).

Since the seminal paper by Bonnafous (1987), many studies have attempted to justify the expensive investments associated to high speed rail projects by appealing to the so-called 'attraction effects', also studying the complementarity/substitution effects that emerge with respect to alternative transport modes. When a (usually, midsized) city becomes a member of the 'HSR club', its visibility within the transport network is enhanced and its attractiveness for outsider visitors is notably increased. (Only) if this happens, the investment pays out and the tale becomes a story of selffulfilling success. However, it is not always clear that changes in local tourism figures can be always attributable to the development of a nearby HSR station and, therefore, empirical measurements of these real spillover effects are urgently required. 
This is precisely the gap this paper intends to fill. Its major contribution is to try to empirically ascertain - with a panel database of Spanish municipalities for the 20052012 period - to what extent AVE affects local tourism when other explaining factors are adequately controlled for. To do so, we use a contra factual 'difference in difference' methodology to identify the cities and towns with or without high-speed stations in their vicinity and then estimate the real (economic) impact of these projects on them.

To carry out this analysis, and after this short introduction, the structure of the paper is as follows. Section 2 provides an extensive literature review on the impacts of HSR on tourism, focusing on the relationship between this mode and alternative ones. Section 3 introduces the database and defines the main variables used in this study. In Section 4 we explain our empirical strategies and models and perform the estimations, subsequently discussing the results. Section $\mathbf{5}$ is finally devoted to conclusions.

\section{The impact of HSR on tourism: a literature review ${ }^{1}$}

Previous literature has studied the link between new HSR stations and tourism outcomes under different approaches. In general, improvements in accessibility of a touristic destination are expected to promote the revitalization of urban and business tourism due to a reduction of the generalized cost of transportation. At least, this positive expected impact is common in the approach of recent studies (see Delaplace and Perrin, 2013; Masson and Petiot, 2009; Bazin et al. 2010) and also appears in the motivation of HSR projects when presented by policy makers and HSR promoters. In fact, tourism gains are among the most common economic positive externalities that are often claimed to be associated with HSR investments. For this reason anticipated gains from HSR due to tourism are present in many recent studies analysing prospect HSR projects (see Murakami and Cervero, 2012; Edwards, 2012; Chen and Haynes, 2012, among others). No doubt, this expected improvement of the touristic attractiveness of destinations, if true, becomes an opportunity to renew the tourist supply for the industry (see Delaplace et al. 2014; Feliu, 2012) and a positive external boost for the local economy (see Hernández and Jiménez, 2014).

Nonetheless, the ex-post evaluation of the relationship between HSR and its effects is much more modest. Bazin et al. (2006) studied impacts of the French HSR (TGV) new services in France on different economic sectors between 1990 and 1999. Among them, they found that they do not stimulate curiosity, except for a sporadic initial demand to become familiar with the service. The analysis of the available experience shows that the availability of HSR gives value to already known and popular tourist destinations but is not sufficient on itself to promote further development. Although initial impacts on visitors' figures may be positive, a surprising result found by several authors is a decrease in the number of overnight stays (acknowledged, for

\footnotetext{
${ }^{1}$ Note there is a wide and well known literature showing the importance of transport infrastructure as a driver of economic development, including tourism. However, we devote this section to the sole case of HSR in order to keep a focus on the direct relationship between this mode of transportation and tourism. For a wider and recent view on transport and development see Hickman et al. (2015).
} 
example, in Bonnafous, 1987 or Klein and Claisse, 1997) and a change in the type of visitor, now more oriented to business travel. In some cities this even produced that small hotels with limited attractions disappeared, while large national chains increased their offer, providing better quality, more appropriate to the characteristics of business tourism. HSR impacts on purely leisure tourism are much more limited, and several projects developed under the expectation of a visitors' increase had to be abandoned. Interestingly, Bazin et al. (2013) restricted their analysis to the TGV effect in tourist destinations reachable in a less than 1.5 hour trip to/from Paris and found that the effects of TGV openings were not long lasting. They also confirmed that improved accessibility had the effect of reducing the number of overnight stays. This suggests that an increase in traffic volume does not imply an increase in demand for local services.

In some other recent works focused on tourist areas in Spain, results are also consistent with this modest impact. For example, Clavé et al. (2015) show that the influx of tourism due to the AVE connection is irrelevant in the area of the coast of Tarragona. In Alicante, Ortuño-Padilla et al. (2015) estimate an increase of just over 20,000 tourists per year in the province after the link to Madrid and Valencia was opened, and the total gross economic impact was about €3-4 million, which is irrelevant in relation to the cost of the line. Finally, Albalate and Fageda (2016) find only inconsistent and weak direct effects of HSR on tourism in Spanish provinces. They also find clear negative indirect effects on air services, which may be a source of concern respect total tourist arrivals if HSR is not able to divert these tourists to the rail, which is unlikely in the case of international tourists. According to results reported in most of their econometric models, the number of tourists grew at a similar rate over the last years in destinations (Spanish provinces) not connected to the HSR network than in destinations connected to it, indicating that factors other than the availability of this service may have a higher influence on tourist attraction of provinces. ${ }^{2}$

On the other hand, it is also well known that HSR generates a centralization effect of economic activities towards big nodes (Givoni, 2006; Haynes, 1997; Van den Berg and Pol, 1998). This effect has also been identified in tourist activities because city size appears to be a relevant determinant of HSR impacts on tourism (see Delaplace, 2012 and Bazin et al., 2013). According to SEEDA (2008) few cities experienced a significant increase of tourist arrivals after HSR openings in Europe, but particularly small and medium-sized cities received very limited increases of tourist arrivals, whereas larger effects could be only identified in some larger cities. Among intermediate cities, only those pre-equipped by tourist amenities enjoyed significant impacts, a result which was also typically observed in the Japanese, Taiwanese and Chinese experiences (Okabe, 1979; Cheng, 2009; Wang et al. 2012 and Chen and Haynes, 2012).

A reason for this unexpected lack of significant impact at the local level should be found in how HSR availability affects destination choice. Pagliara et al. (2015) studies the impact of HSR in Madrid on tourist destination choice by means of a

\footnotetext{
${ }^{2}$ Coronado et al (2013) focused on observed tourist mobility and they have shown the potential interest of HSR for same-day tourism.
} 
revealed preference survey. Results indicate that the presence of HSR does not seem to be a key factor influencing the destination choice of tourists because most of them are international tourists that can only arrive by air transportation. However, the use of HSR appears to be attractive to international tourists to visit nearby locations only. A similar conclusion is reached by Chen and Haynes (2015) when investigating the impact of the Chinese high-speed rail systems on its international tourism demand. These authors find very small demand elasticity with respect to the existence of HSR stations. Their results indicate that "a $1 \%$ increase in HSR station is associated with a $0.057 \%$ increase in international tourism arrivals, ceteris paribus." (Chen and Haynes, 2015, p. 59). Thus, tourism does not seem to be influenced by HSR availability and this becomes a major barrier to anticipate positive impacts from rail transport onto the tourism industry.

As noted by these studies, tourism decisions may be determined by the interaction between HSR and air transportation. Positive impacts from HSR are expected from increasing the overall number transport users or by promoting a given type of visitor (high income, longer stays, etc.). However, HSR usually exerts a substitution or even predatory effect on air transportation. Indeed, a growing literature has emerged on the modal competition between high-speed rail and air transportation in recent years (see Givoni and Dobruszkes, 2013 for a review). HSR harms air transportation above all alternative modes due to its ability to attract a relative large market share in medium distances. For this reasons HSR becomes one of the main determinants of market power loss for traditional carriers (Zhang et al., 2014) and a strong entry barrier for new airlines (Kappes and Merkert, 2013). Since the relationship between air transport and tourism as two deeply interconnected activities is well established in the literature, the potential damage that HSR may exert to the airline industry will definitely affect net tourism outcomes (Rey et al., 2011; Dobruszkes and Mondou, 2013).

The substitution effect evidence has been extensively recognised for all countries with HSR lines, ${ }^{3}$ and beyond national experiences and pre-post comparisons, Clewlow et al. (2012), Dobruszkes et al. (2014) and Albalate et al. (2015a) also confirm this substitution effect with a sample of European routes and a variety of econometric techniques. Similar impacts on air transportation are documented for Asian experiences, as happened in Korea (Suh et al., 2005; Lee et al., 2012), China (Fu et al., 2012; Wu 2013) and Taiwan (Yung-Hsiang Cheng, 2010).

Although several papers have explored the cooperation possibilities between both modes (see, for example, Givoni and Banister, 2006 and Dobruszkes et al., 2014), and some have even found several specific cooperation programs between HSR and air carriers (Dobruszkes, 2011), most HSR network designs have been oriented to replicate routes and compete with air transportation. Therefore, it is not surprising that empirical research has been unable to find systematic complementarities, even though some potential for them seems available in hub airports due to the airlines

\footnotetext{
${ }^{3}$ The evidence covers from the first lines in Japan (Taniguchi, 1992; Clever and Hensher, 2008), to the EU countries that followed: France (Vickerman, 1997; Klein, 1997), Spain (COM, 1996; Román et al., 2007; Martín and Nombela, 2008; Jiménez and Betancor, 2012; Pagliara, Vassallo and Román, 2012), Italy (Cascetta et al., 2011) and Germany (Ellwanger and Wilckens, 1993; Dobruszkes, 2011).
} 
feeding strategies and the presence of HSR stations within airport premises (Albalate et al., 2015a).

In sum, most of the previous works have focused on the role of HSR on cityroute tourism case studies, or integrated within the national transport system. They have mainly considered the (expected) changes pre-HSR inaugurations, but most of these expectations to enhance local tourism have not been proven. This study contributes to this literature by being the first to estimate empirically the impact of HSR on local tourism using a sample of municipalities and considering all HSR lines in a large and touristic country as Spain. We also intend to provide some novel empirical evidence on this issue using a quasi-experimental setting based on both the 'differences in differences' methodology and a panel data analysis that allows us to measure the impact of HSR availability and its territorial effects by considering the distance from/to HSR stations. A description of our database and empirical strategy follows in next sections.

\section{Database and variable description}

The main questions addressed in this paper are the following ones: (1) does the provision of high speed rail services (AVE) have a significant impact on tourism at the city level in Spain? (2) can we quantify this impact?, and finally, (3) would this impact be different without the AVE? To study these local effects, we have built a database that encompasses all the relevant tourism information both of those municipalities where new AVE stations were built or enhanced and of those (contra factual) municipalities without HSR entry. Our monthly data covers the period 2005-2012, when six major HSR projects started to operate, connecting at least 12 provinces capital-cities and more than 30 other medium-sized and smaller towns (see Figure 1). ${ }^{4}$

\footnotetext{
${ }^{4}$ In particular, these new HSR projects represented in Figure 1 arrived at the following cities and towns at the given dates: Toledo (November 2005; pop. 75,533), Tarragona (December 2006; pop. 131,158), Valladolid (December 2007; pop. 316,564); Malaga (December 2007; pop. 561,250), Segovia (December 2007; pop. 55,942), Barcelona (February 2008; pop. 1,616,000), Albacete (December 2010; pop. 170,475), Cuenca (December 2010, pop. 55,738), Valencia (December 2010; pop. 809,267), Ourense (December 2011; pop. 108,002), A Coruña (December 2011; pop. 246,028) and Santiago (December 2011; pop. 95,207). The line connecting Barcelona and the French border was opened in 2013 and is not included in this paper.
} 
Figure 1. High-speed rail (AVE) lines inaugurated between 2005 and 2012 in Spain

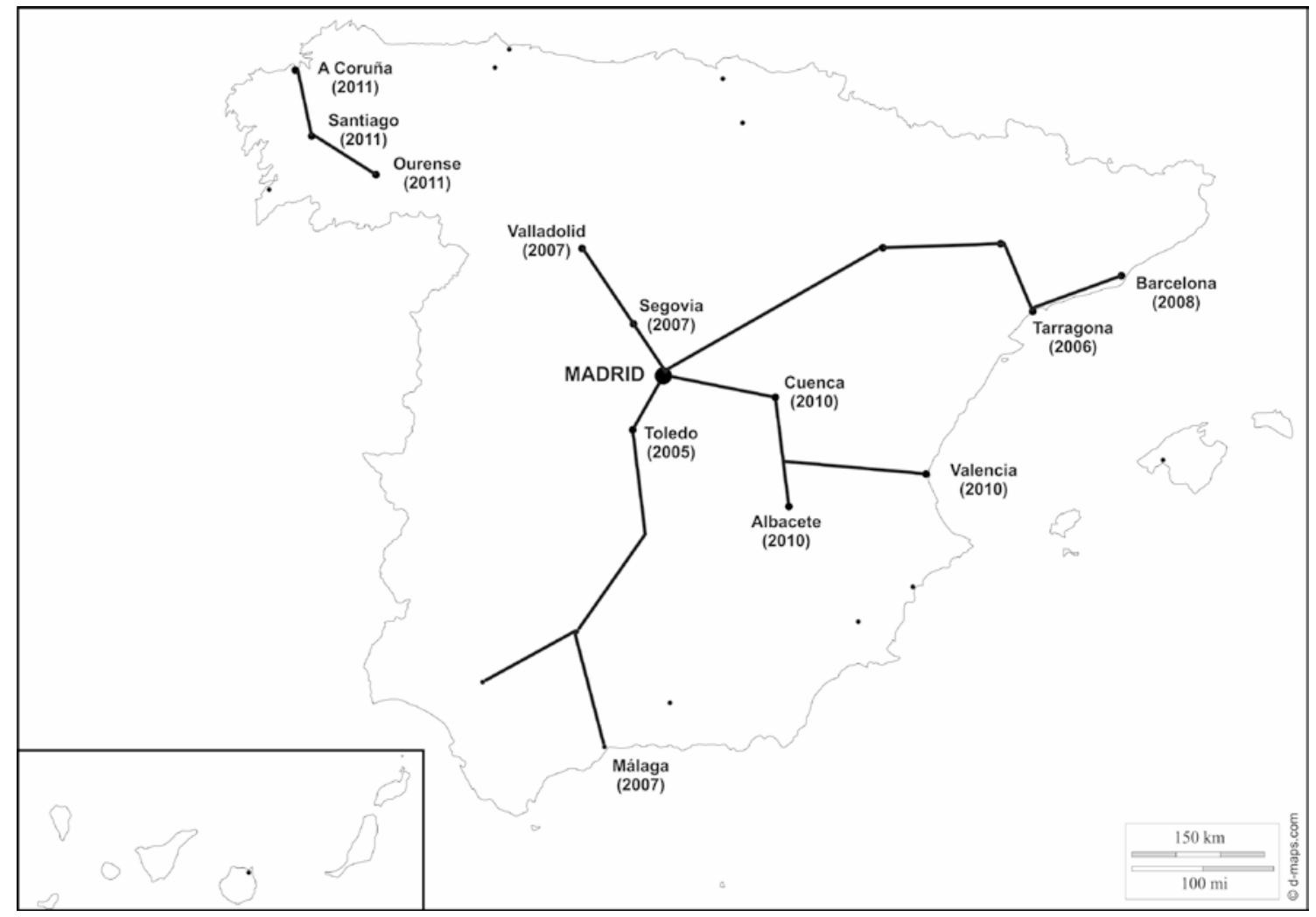

Source: Own elaboration from www.adifaltavelocidad.es (Spain's rail network manager).

Adapted from www.d-maps.com, with permission.

Thus, for those 12 cities and other 112 municipalities with tourism relevance (known as 'tourism interest point', as defined by the Spanish National Statistical Office - www.ine.es - attending to their tourism supply facilities) ${ }^{5}$, we have collected the following main variables:

- VISITORSimt: total number of overnight visitors (spending one or more nights) at the tourism interest point $i$, during month $m$ of year $t$. This variable can be separated into national (i.e., Spanish) and foreign visitors and its main source is the 'Hotel Occupancy Survey' (Encuesta de Ocupación Hotelera, available at www.ine.es), which describes tourism demand in Spain. ${ }^{6}$

\footnotetext{
${ }^{5}$ Additional official information regarding which accommodations are considered can be accessed through the following website http://www.ine.es/daco/daco42/ocuphotel/notaeoh.htm (Accessed 26/05/2016). The data source includes includes tourism establishments registered as such in the register of the Regional Council of Tourism of each Regional Government. It would include accommodations that provide collective accommodation by price with or without complementary services (hotel, apartment hotel or apartment, motel, hostel, pension, etc.).

6 It is relevant to note that we are just considering overnight visitors, excluding one-day excursionists. Our underlying assumption is that most excursionists rely on bus, taxi or car rental as their main transport mode, instead of rail services (for one-day return trips). We do not have detailed information on the transport mode chosen by each traveller. Similarly, we do not have detailed expenditure surveys
} 
- Total overnight Staysimt: total number of nights spent by the total number of visitors (also separated into national and foreign) at hotels and other tourism accommodations at tourism interest point $i$, during month $m$ of year $t$, with the same data source.

- Average StaYimt: defined as the ratio between the total overnight stays and the total number of visitors, and provides the number of nights that on average each visitor spends at destination. A larger average stay is usually associated to a higher level of expenditure.

- Occupancy RATEimt: this variable (given as a percentage) is the ratio between the total overnight stays and the tourism supply (temporary and permanent hotel beds multiplied by the days they are available), as provided again by the 'Hotel Occupancy Survey'.

- Hotel PRICE INDEX $\boldsymbol{j}_{\text {jmt: }}$ this index summarizes the monthly evolution of hotel prices taking into account their location and category. It is specifically calculated by the Spanish National Statistical Office for the 'Tourist Accommodation Survey' (Encuesta de Alojamientos Turísticos, also available at www.ine.es, which describes tourism supply in Spain. The subscript $j$ refers to the corresponding region (Autonomous Community) since this index is not disaggregated at local level.

- Population it: total number of residents in municipality $i$ at the end of year $t$, according to the Anuario Económico de La Caixa (La Caixa Yearbook), a database which contains information on more than 3,000 municipalities in Spain, and is online available at www.anuarieco.lacaixa.comunicacions.com

- AIRPORTimt: binary and own-elaborated variable that takes value 1 after the enlargement or major enhancement of airports located at municipality $i$, in order to capture potential effects on tourism associated to other transport modes. This variable refers to infrastructure changes to account for main infrastructure changes of long distance alternative modes. This includes the construction or expansion of new terminals or new runways.

- Flag_CARRIERit: this is the annual market share of the Spanish flag carrier Iberia and its regional subsidiary regional airline, Air Nostrum, in the closest airport to municipality $i$. The Air transportation industry experienced an important restructuring during the time span considered due to the increasing share of low cost carriers at the expense of regular carriers. This dramatic change coincided with the deployment of the HSR network. For this reason we introduced a new variable to capture this process that could offset the potential of HSR to attract tourism given that low cost airlines tend to be more successful in competing with HSR. Thus, we expect a negative relationship between this variable and our dependent variable. We obtained data from the Spanish Manager of Airports (AENA).

- HSRINXKM imt $_{\text {: }}$ binary variable that takes value 1 at those neighboring municipalities that are located within $\boldsymbol{X}$ kilometers of an AVE station in municipality $i$, during month $m$ of year $t$, according to our own elaboration. In estimations we detailed at

and consider therefore that most of this (tourist) expenditure is proportional to the number of nights spent at destination. 
section 4, we consider binary variables for those municipalities surrounding HSR in 10-20 or 20-50 kms. Source: own elaboration.

In addition to this standard set of main variables on tourism and transport, we needed to build ad-hoc variables for the counter-factual testing our empirical strategy in the difference-in-difference (DiD hereafter) methodology. In particular, three specific variables were used:

- Treatedimt: is a dummy that takes value 1 if it refers to a municipality where the AVE entered in the 2005-2012 period (see footnote 4, for details). The objective of this variable is to control for a potentially different behaviour between these municipalities and the remaining ones (defined as the control group), although we can also consider those municipalities that already had an AVE connection before the 2005-2012 period.

- After $t$ : is a covariate that controls for potential seasonal effects on the endogenous variables (i.e., tourism figures) that could affect all the municipalities included in the treatment group (i.e., those that benefitted from an AVE project). It takes value 1 for all these municipalities after the AVE inauguration. Note that in the DiD analysis we will have to deal with six different 'AFTER' variables, due to different inauguration dates ( $t$, see again footnote 4).

- $\mathbf{D I D}_{\text {imt }}$ : is the double difference, that is, the actual difference-in-difference estimator and takes value 1 for the treatment group in the 'AFTER' period. This variable shows how the endogenous variables are changed for the municipalities affected by the AVE as strictly compared to those not affected by it.

Table 1. Summary of average monthly data by type of municipality (2005-2012)

\begin{tabular}{|c|c|c|c|c|c|c|}
\hline & $\begin{array}{c}\text { Total } \\
\text { number } \\
\text { of visitors }\end{array}$ & $\begin{array}{l}\text { National } \\
\text { visitors } \\
(\%)\end{array}$ & $\begin{array}{c}\text { Foreign } \\
\text { visitors } \\
(\%)\end{array}$ & $\begin{array}{l}\text { Total } \\
\text { Overnight } \\
\text { stays }\end{array}$ & $\begin{array}{c}\text { Average } \\
\text { stay } \\
\text { (nights) }\end{array}$ & $\begin{array}{c}\text { Occupancy } \\
\text { rate (\%) }\end{array}$ \\
\hline & \multicolumn{6}{|c|}{ In municipalities with a new AVE project in the 2005-2012 period } \\
\hline Before the HSR project & $\begin{array}{c}48,328 \\
(78,677)\end{array}$ & $\begin{array}{c}70.9 \\
(21.0)\end{array}$ & $\begin{array}{c}29.1 \\
(21.0)\end{array}$ & $\begin{array}{c}132,162 \\
(221,201)\end{array}$ & $\begin{array}{c}2.59 \\
(1.81)\end{array}$ & $\begin{array}{c}48.9 \\
(15.6)\end{array}$ \\
\hline \multirow[t]{2}{*}{ After the HSR project } & $\begin{array}{c}47,768 \\
(89,620)\end{array}$ & $\begin{array}{c}67.5 \\
(24.6)\end{array}$ & $\begin{array}{c}32.5 \\
(24.6)\end{array}$ & $\begin{array}{c}159,439 \\
(271,534)\end{array}$ & $\begin{array}{c}2.96 \\
(1.98)\end{array}$ & $\begin{array}{c}47.5 \\
(17.8)\end{array}$ \\
\hline & \multicolumn{6}{|c|}{ In municipalities without a AVE project in the 2005-2012 period } \\
\hline \multirow[t]{2}{*}{ For all the period } & $\begin{array}{c}32,588 \\
(37,594)\end{array}$ & $\begin{array}{c}67.2 \\
(26.0)\end{array}$ & $\begin{array}{c}32.8 \\
(26.0)\end{array}$ & $\begin{array}{c}144,702 \\
(236,846)\end{array}$ & $\begin{array}{c}3.27 \\
(2.14)\end{array}$ & $\begin{array}{c}48.2 \\
(18.7)\end{array}$ \\
\hline & \multicolumn{6}{|c|}{ In municipalities with a AVE project before the 2005-2012 period } \\
\hline For all the period & $\begin{array}{c}185,684 \\
(228,040)\end{array}$ & $\begin{array}{c}65.1 \\
(14.3)\end{array}$ & $\begin{array}{c}34.9 \\
(14.3)\end{array}$ & $\begin{array}{c}352,356 \\
(452,322)\end{array}$ & $\begin{array}{c}1.74 \\
(18.2)\end{array}$ & $\begin{array}{c}46.9 \\
(12.4)\end{array}$ \\
\hline
\end{tabular}

Source: Own elaboration. Standard deviation in brackets. 
Table 1 summarizes some of the average values of our main tourism-related variables by separating them into three different groups: those corresponding to municipalities that enjoyed a new AVE project in the 2005-2012 period, those that did not, and those that had a previous AVE development. As mentioned above, we only focused on 'tourism interest points', which excludes very small municipalities that could distort the results. In fact, the average population in the first group (not showed in the table) is 355,928 inhabitants, whereas in the other groups is 145,762 inhabitants. In addition, the distribution of coastal vs. interior municipalities is almost 50-50 in all three groups and there are not significant differences in their (regional) average hotel prices, adjusted per quality.

Some interesting features deserve a final comment. Firstly, the third group is the most relevant from the point of view of tourism, since it includes the initial and most successful lines (which started in 1992 with the Madrid-Seville). Secondly, the municipalities with new AVE projects did not experienced a substantial tourism growth (in fact, a $-1.1 \%$ decline), although their total and average stays increased. Finally, the municipalities without AVE had also large average stays and occupancy rates. Since it seems that the effects of AVE are not so clear, additional statistical analysis is performed in the following section. 


\section{Quantifying the impact of AVE on local tourism}

The quantification of the impacts of high-speed projects on local tourism can be addressed from different point of views (see Section 2). In this paper we have specifically chosen a quasi-experimental approach that compares Spanish municipalities that benefitted from AVE projects in the 2005-2012 period with those that did not (either because they already had them or because they did not receive such investments at all).

From an empirical point of view, our strategy relies on two complementary approaches: one based on the 'difference-in-difference methodology' (DiD), and other on standard panel data. The DiD technique is appropriate when the 'treatment' cannot be considered random or only depending on observed characteristics. ${ }^{7}$ Thus, it evaluates policy impacts by accepting the existence of pre-intervention differences between the treated and the control group that may be observable and unobservable. This unobserved heterogeneity is assumed to be constant over time, so computing the difference between the within-group variation of the outcome variable from the pretreatment period to the post-treatment period may be enough to identify an unbiased treatment impact. ${ }^{8}$

In addition to this strategy, we also use panel data methods in order to better account for heterogeneity. Panel data methods allows us to evaluate the HSR impact on all municipalities considered simultaneously. The unobserved heterogeneity may be also considered by introducing a fixed effect that identifies each municipality and the year considered using the standard fixed effects model. This two way fixed effects model can also be considered a generalisation of the DiD method to Panel methods. ${ }^{9}$ Note that fixed effects is providing unbiased estimates of the impact of HSR, while the Random Effects model might provide efficient but biased estimates. Additonally, the Hausman Test suggests the use of the fixed effects models but main results do not seem to be affected by this decision given that random effects models provide very similar results in terms of coefficients and statistical significance. ${ }^{10}$

In both cases, our endogenous variables are those related to tourism inflows on a particular municipality (TOURISM), namely, the total number of visitors (separated into national and foreign), the total number of overnight stays, the average stay per visitor and the occupancy rate. Note that, as discussed above, we are implicitly assuming that tourism expenditure is proportional to the number of nights spent at destination and

\footnotetext{
${ }^{7}$ Under this assumption, simple matching and propensity score matching would be more appropriate.

8 In particular, the difference-in-difference estimator is the difference in average outcome in the treatment group before and after treatment minus the difference in average outcome in the control group before and after treatment. In our case, treatment group are those cities where HSR start to operate, control were not, and treatment is the moment in which it started.

${ }^{9}$ Note that these fixed effects should capture both idiosyncratic effects (local history and monuments, cultural ties, local gastronomy, etc.) and the specific endowment of infrastructure (e.g. roads) and other effects (weather conditions) that do not change every year.

${ }^{10}$ Random Effects model results are available upon request.
} 
therefore, these TOURISM variables indirectly calibrate the impact of high-speed rail projects on local economies.

Note that one could argue that our policy variable could be endogenous biasing our results on the impact of HSR investments on Tourism outcomes. This could make sense if touristic activity would have been one of the drivers of HSR investment decisions. Endogeneity would emerge if HSR were placed precisely in touristic municipalities and not in municipalities without relevant touristic activity. Although this is a plausible economic argument, it has nothing to do with the reality in Spain. HSR establishments have not been related to how touristic is a municipality, but related to the status of being a province capital. This is described in Albalate and Fageda (2016) that explains why Spain becomes a good case to study HSR and Tourism precisely due to the absence of this kind of endogeneity. Also Bel (2010) and Albalate and Bel (2011) show that the distribution of decisions regarding HSR investments have neglected the main economic aspects and have followed just an administrative pattern. The objective of the policy has been and still is connecting Madrid to all provincial capitals. Indeed, HSR has been placed in many municipalities without touristic activity and many other cities with high touristic activity have not received this investment. Recent evidence by Shen et al. (2014) suggests for example that land-planning criteria is a major driver of investment decisions in countries where regional cohesion is at stake, as could be in Spain.

Our DiD model is based on the following semi-log equation that facilitates the interpretation of coefficients in terms of semi-elasticities. ${ }^{11}$ The first line on its righthand side captures the 'difference' effects, the second line refers to the existing transport infrastructure, the third one corresponds to other factors related to city-size and tourism demand (population and hotel prices) and the last line captures cycle and seasonal effects; $\varepsilon_{i m t}$ is the usual error term: ${ }^{12}$

$$
\begin{aligned}
\text { In(TOURISM })_{i m t} & =\beta_{0}+\beta_{1} \text { After }_{m t}+\beta_{2} \text { Treated }_{i}+\beta_{3} \text { DiD }_{i m t}+\beta_{4} \text { Airport }_{i} \\
+ & \beta_{5} \text { HSR10km }_{i m t}+\beta_{6} \text { HSR2Okm }_{i m t}+\beta_{7} \text { HSR50km }_{i m t}+\beta_{8} \text { Population }_{i t} \\
& +\beta_{9} \text { Population }_{i t}+\beta_{10} \text { Hotelprices }_{i t}+\beta_{11} \text { Flag_carrier }_{i t} \\
& +\sum_{h=12}^{21} \beta_{h} \text { Year effect }_{t}+\sum_{h=22}^{33} \beta_{h} \text { Monthly effect }_{t}+\varepsilon_{i m t}
\end{aligned}
$$

Table 2 summarizes some of the estimation results of the DiD model. The columns correspond to the (log of the) TOURISM dependent variable, and each row reflects the impact of high-speed rail on selected municipalities. According to Figure 1

\footnotetext{
${ }^{11}$ Also, Box-Cox tests on specification and functional form provide better fit with semi-log specifications than with other linear or double-log alternatives.

12 Model estimation has been performed ensuring robustness with regard to heterokedasticity problems, and clustering municipalities to avoid heterogeneity issues. Also, we computed variance inflation factors to evaluate multicolinearity finding an average VIF of 5, well below the regular rule of thumb of 10 .
} 
(and footnote 4) there were six major new AVE undertakings in the 2005-2012 period but we split them into separate estimations by municipalities. We focused our attention on the province capitals reported in Table 2 . Then, in order to isolate the specific effects of HSR, for each of these we excluded (on each estimation) the municipalities where the AVE projects started later, before or simultaneously. The average $\mathrm{R}^{2}$ for all estimations is close to 0.35 . 
Table 2. DiD coefficients on the effects of AVE on selected cities

\begin{tabular}{|c|c|c|c|c|c|c|}
\hline $\begin{array}{l}\text { Dep. variable } \\
\text { Effect of AVE on... }\end{array}$ & Visitors & $\begin{array}{l}\text { Overnight } \\
\text { stays }\end{array}$ & $\begin{array}{l}\text { Average } \\
\text { stay }\end{array}$ & $\begin{array}{l}\text { National } \\
\text { visitors }\end{array}$ & $\begin{array}{l}\text { Foreign } \\
\text { visitors }\end{array}$ & $\begin{array}{l}\text { Occupancy } \\
\text { rate }\end{array}$ \\
\hline ...Toledo & $\begin{array}{l}-0.07 \\
(0.05)\end{array}$ & $\begin{array}{l}0.001 \\
(0.07)\end{array}$ & $\begin{array}{c}0.06 \\
(0.02)^{* *}\end{array}$ & $\begin{array}{l}-0.02 \\
(0.04)\end{array}$ & $\begin{array}{l}-0.14 \\
(0.09)\end{array}$ & $\begin{array}{l}-0.03 \\
(0.02)\end{array}$ \\
\hline ...Tarragona & $\begin{array}{c}-0.24 \\
(0.04)^{* * *}\end{array}$ & $\begin{array}{c}-0.23 \\
(0.04)^{* * *}\end{array}$ & $\begin{array}{l}0.004 \\
(0.01)\end{array}$ & $\begin{array}{c}-0.34 \\
(0.03)^{* * *}\end{array}$ & $\begin{array}{l}-0.005 \\
(0.06)\end{array}$ & $\begin{array}{c}-0.06 \\
(0.01)^{* * *}\end{array}$ \\
\hline ...Valladolid & $\begin{array}{c}0.07 \\
(0.04)^{*}\end{array}$ & $\begin{array}{c}0.06 \\
(0.05)\end{array}$ & $\begin{array}{l}-0.02 \\
(0.02)\end{array}$ & $\begin{array}{c}0.11 \\
(0.04)^{* * *}\end{array}$ & $\begin{array}{c}0.02 \\
(0.07)\end{array}$ & $\begin{array}{c}-0.04 \\
(0.02)^{* *}\end{array}$ \\
\hline ...Segovia & $\begin{array}{c}0.10 \\
(0.04)^{* *}\end{array}$ & $\begin{array}{c}0.13 \\
(0.05)^{* *}\end{array}$ & $\begin{array}{c}0.02 \\
(0.02)\end{array}$ & $\begin{array}{c}0.15 \\
(0.04)^{* * *}\end{array}$ & $\begin{array}{c}0.03 \\
(0.07)\end{array}$ & $\begin{array}{c}-0.05 \\
(0.02)^{* * *}\end{array}$ \\
\hline ...Málaga & $\begin{array}{c}0.46 \\
(0.12)^{* * *}\end{array}$ & $\begin{array}{c}0.31 \\
(0.14)^{* *}\end{array}$ & $\begin{array}{l}-0.15 \\
(0.07)^{* *}\end{array}$ & $\begin{array}{c}0.49 \\
(0.14)^{* * *}\end{array}$ & $\begin{array}{c}0.56 \\
(0.18)^{* *}\end{array}$ & $\begin{array}{c}0.12 \\
(0.06)^{*}\end{array}$ \\
\hline ...Barcelona & $\begin{array}{c}0.23 \\
(0.15)\end{array}$ & $\begin{array}{c}0.08 \\
(0.18)\end{array}$ & $\begin{array}{c}-0.15 \\
(0.08)^{*}\end{array}$ & $\begin{array}{c}0.33 \\
(0.18)^{*}\end{array}$ & $\begin{array}{c}0.11 \\
(0.21)\end{array}$ & $\begin{array}{c}0.14 \\
(0.07)^{* *}\end{array}$ \\
\hline ...Valencia & $\begin{array}{c}0.06 \\
(0.06)\end{array}$ & $\begin{array}{l}-0.003 \\
(0.09)\end{array}$ & $\begin{array}{c}-0.07 \\
(0.04)^{*}\end{array}$ & $\begin{array}{c}0.15 \\
(0.05)^{* * *}\end{array}$ & $\begin{array}{l}0.006 \\
(0.11)\end{array}$ & $\begin{array}{c}0.07 \\
(0.03)^{* *}\end{array}$ \\
\hline ...Cuenca & $\begin{array}{c}-0.12 \\
(0.04)^{* *}\end{array}$ & $\begin{array}{c}-0.21 \\
(0.06)^{* * *}\end{array}$ & $\begin{array}{c}-0.09 \\
(0.02)^{* * *}\end{array}$ & $\begin{array}{c}-0.09 \\
(0.03)^{* * *}\end{array}$ & $\begin{array}{c}0.08 \\
(0.08)\end{array}$ & $\begin{array}{c}-0.18 \\
(0.02)^{* * *}\end{array}$ \\
\hline ...Albacete & $\begin{array}{c}-0.08 \\
(0.04)^{*}\end{array}$ & $\begin{array}{c}-0.23 \\
(0.06)^{* * *}\end{array}$ & $\begin{array}{c}-0.15 \\
(0.02)^{* * *}\end{array}$ & $\begin{array}{l}-0.01 \\
(0.03)\end{array}$ & $\begin{array}{l}-0.05 \\
(0.08)\end{array}$ & $\begin{array}{c}-0.38 \\
(0.02)^{* * *}\end{array}$ \\
\hline ...Santiago & $\begin{array}{c}0.13 \\
(0.29)\end{array}$ & $\begin{array}{l}-0.21 \\
(0.40)\end{array}$ & $\begin{array}{c}-0.34 \\
(0.17)^{* *}\end{array}$ & $\begin{array}{c}0.53 \\
(0.23)^{* *}\end{array}$ & $\begin{array}{l}-0.16 \\
(0.50)\end{array}$ & $\begin{array}{c}0.04 \\
(0.09)\end{array}$ \\
\hline ...Coruña & $\begin{array}{c}-0.21 \\
(0.04)^{* * *}\end{array}$ & $\begin{array}{c}-0.12 \\
(0.05)^{* *}\end{array}$ & $\begin{array}{c}0.08 \\
(0.02)^{* * *}\end{array}$ & $\begin{array}{c}-0.16 \\
(0.03)^{* * *}\end{array}$ & $\begin{array}{c}-0.12 \\
(0.06)^{*}\end{array}$ & $\begin{array}{c}-0.11 \\
(0.02)^{* * *}\end{array}$ \\
\hline
\end{tabular}

Note: ${ }^{* * *} 1 \%,{ }^{* *} 5 \%,{ }^{*} 10 \%$ significance test. Standard deviation in brackets. Ourense was not finally included in the estimations because 2011 data were not complete.

The first row in Table 2, for example, compares the (mid-sized) city of Toledo (see Figure 1), where the AVE arrived in November 2005, with the remaining municipalities that never enjoyed this investment. The effect of HSR is negative with regard to almost all the dependent variables, although only statistically significant in the last two columns. In the smaller city of Tarragona (December 2006) the estimated coefficients are also negative with respect to most dependent variables (particularly, the number of national visitors), whereas in other cities positive and negative signs are more evenly distributed.

Interestingly, Malaga appears to be the only city that enjoyed consistently positive effects in almost all dependent variables considered. Also Barcelona shows some positive effects. On the one hand, on the number of national visitors that increased by $33 \%$. On the other, on the occupancy rate, which grew by $14 \%$ (although the average stay fell 15\%). Valencia also presents some similar but smaller effects, with positive impacts on the number of national visitors (15\%) as well as on the occupancy rate $(7 \%)$. Also in this case the average stay decreased by $7 \%$. 
Note that these three are the main cities of three of the most touristic regions with beach destinations (attractive for both domestic and international tourists).Moreover, this result would be consistent with the literature cited above claiming that HSR services tend to centralize economic activity to main cities. Big nodes tend to drain the economic activity of other mid-size cities.

In general, the DiD estimates in Table 2 allows us to quantify (if any) the impact of AVE projects in the 2005-2012 period on selected Spanish municipalities as compared to control groups where these undertakings did not take place or they did in other periods. As discussed above, a complementary approach to focus on this issue consists in estimating a panel equation that simultaneously considers all the municipalities, but adding a dummy variable AVE PROJECT $T_{T}$, to capture the specific existence (value 1) or not (value 0 ) of an AVE project on each city every year and from that onwards. As mentioned, we implement the two way fixed effect model to generalize the DiD strategy to panel data and due to the advise of the Hausman Test.

The new equation would be in this case:

$$
\begin{aligned}
\ln _{\text {(TOURISM })_{i m t}} & =\beta_{0}+\beta_{1} \text { AVE project }_{i m t}+\beta_{2} \text { Airport }_{i m t}+\beta_{3} \text { HSR1Okm }_{i m t} \\
& +\beta_{4} \text { HSR2Okm }_{i m t}+\beta_{5} \text { HSR5Okm }_{i m t}+\beta_{6} \text { Population }_{i t} \\
& +\beta_{7} \text { Population }_{i t}+\beta_{8} \text { Hotelprices }_{j t}+\beta_{9} \text { Flag_carrier }_{i t} \\
& +\sum_{h=10}^{19} \beta_{h} \text { Year effect }_{t}+\sum_{h=20}^{31} \beta_{h} \text { Monthly effect }_{t}+\varepsilon_{i t}
\end{aligned}
$$

where the interpretation of the endogenous and exogenous variables is similar to that in the previous equation. In fact, as showed in the following tables, for each of the six TOURISM dependent variables (total number of visitors, overnight stays, average stay, national visitors, foreign visitors and occupancy rates) three different panel models have been estimated. Model 1 includes all the dummies, plus the fixed year and monthly effects, but excluding all the municipalities that had AVE during the entire sample period (that is, we consider only the municipalities where some change did occur in 2005-2012). Model 2 includes all the remaining independent variables in this sample, and finally, Model 3 also includes all the municipalities.

Table 3 summarizes the results from these estimations when the dependent variable is the total number of visitors. Again, confirming (as expected) the results from the DiD model, we find no clear trends, since the estimate coefficients for the impact of the AVE project (first row) are positive and negative in each model, but not statistically significant. In Table 4, where we intend to assess the AVE effect on overnight stays, again the key coefficients are not significant, although - on the contrary - airport enlargements seems to play a more relevant role of tourism (a 15\% effect according to Model 3). Table 5 confirms - once more - that the AVE has no significant impact on the average stay at destination, whereas the airport does have it (generates a $6 \%$ increase), although the model reduces its significance. Similar results appear in Table 6 with respect to the number of national visitors and only in Table 7 
with respect to foreign visitors we find a relevant effect $(+9 \%)$ of the AVE (although the impact of the airport is still higher, with 15\%). Surprisingly, our final estimates in Table 8 find a negative effect of AVE on the occupancy rates $(-8 \%)$ and positive (in the same amount) associated to airport investments.

One variable that shows a permanent and consistent influence on the number of visitors, overnights and occupancy rates is the market share of the flag carrier Iberia and its subsidiary regional airline Air nostrum. The coefficient associated with the market share of the traditional airline is negatively related to tourism outcomes because this airline has been increasingly substituted by other more efficient and cheaper airlines that are able to provide more tourists to destinations. Because this process of industry restructuring coincided with the main deployment of HSR, our result could indicate an offsetting effect of these low cost airlines on the potential effects of HSR. The effect of this market share is larger for foreign visitors than for national visitors, as indicated by the comparison between Table 6 and Table 7.

Table 3. AVE effect on total number of visitors: panel data estimation (fixed effects).

\begin{tabular}{lccc}
\hline \multicolumn{1}{c}{ Explanatory variables } & Model 1 & Model 2 & Model 3 \\
\hline AVE project & $-0.002(0.04)$ & $0.03(0.05)$ & $0.04(0.05)$ \\
Airport enlargement & $0.08(0.07)$ & $0.07(0.07)$ & $0.09(0.07)$ \\
HSR (in 10-20 km) & $-0.18(0.02)^{* * *}$ & $-0.11(0.02)^{* * *}$ & $-0.13(0.02)^{* * *}$ \\
HSR (in 20-50 km) & $-0.02(0.03)$ & $0.02(0.05)$ & $-0.02(0.04)$ \\
Population & - & $-7 \mathrm{e}-6(2 \mathrm{e}-6)^{* * *}$ & $-3 \mathrm{e}-6(2 \mathrm{e}-6)^{*}$ \\
Population squared & - & $5 \mathrm{e}-12(1 \mathrm{e}-12)^{* * *}$ & $8 \mathrm{e}-13(3 \mathrm{e}-13)^{* * *}$ \\
Hotel prices (regional) & - & $0.007(0.003)^{* *}$ & $0.006(0.003)^{* * *}$ \\
Flag carrier & - & $-0.02(0.004)^{* * *}$ & $-0.02(0.004)^{* * *}$ \\
Year effect & Yes & Yes & Yes \\
Monthly effect & Yes & Yes & Yes \\
Constant & $9.39(0.04)^{* * *}$ & $9.34(0.40)^{* * *}$ & $9.31(0.42)^{* * *}$ \\
\hline Observations & 10,296 & 8,096 & 8,576 \\
& & Excluding & \\
Sample & All sample & municipalities & All sample \\
& with HSR in all & \\
Period & $2005-2015$ & period & $2005-2012$ \\
R $^{2}$ (within groups) & 0.42 & 0.43 & 0.42 \\
\hline
\end{tabular}

Note: ${ }^{* * *} 1 \%,{ }^{* *} 5 \%,{ }^{*} 10 \%$ significance test. Standard errors are shown in brackets. 
Table 4. AVE effect on overnight stays: panel data estimation (fixed effects)

\begin{tabular}{lccc}
\hline Explanatory variables & Model 1 & Model 2 & Model 3 \\
\hline HSR project & $-0.009(0.04)$ & $0.01(0.05)$ & $0.02(0.05)$ \\
Airport enlargement & $0.12(0.08)$ & $0.13(0.07)^{*}$ & $0.15(0.07)^{* *}$ \\
HSR (in 10-20 km) & $-0.11(0.02)^{* * *}$ & $-0.05(0.02)^{* *}$ & $-0.07(0.02)^{* * *}$ \\
HSR (in 20-50 km) & $-0.04(0.04)$ & $-0.003(0.03)$ & $-0.02(0.02)$ \\
Population & & $-7 \mathrm{e}-6(2 \mathrm{e}-6)^{* * *}$ & $-4 \mathrm{e}-6(2 \mathrm{e}-6)^{* *}$ \\
Population squared & & $4 \mathrm{e}-12(1 \mathrm{e}-12)^{* * *}$ & $9 \mathrm{e}-13(3 \mathrm{e}-13)^{* * *}$ \\
Hotel prices (regional) & & $0.008(0.003)^{* * *}$ & $0.008(0.003)^{* * *}$ \\
Flag carrier & Yes & $-0.02(0.004)^{* * *}$ & $-0.02(0.004)^{* *}$ \\
Year effect & Yes & Yes & Yes \\
Monthly effect & Yes & Yes \\
Constant & $10.40(0.05)^{* * *}$ & $10.37(0.42)^{* * *}$ & $10.38(0.45)^{* * *}$ \\
\hline Observations & 10,296 & 8,096 & 8,576 \\
& & Excluding & \\
Sample & All sample & municipalities & All sample \\
Period & & with HSR in all & \\
$\mathrm{R}^{2}$ (Within groups) & period & $2005-2012$ \\
\hline
\end{tabular}

Note: ${ }^{* * *} 1 \%,{ }^{* *} 5 \%,{ }^{*} 10 \%$ significance test. Standard errors are shown in brackets. 
Table 5. AVE effect on average stay: panel data estimation (fixed effects)

\begin{tabular}{lccc}
\hline Explanatory variables & Model 1 & Model 2 & Model 3 \\
\hline HSR project & $-0.008(0.02)$ & $-0.02(0.02)$ & $-0.02(0.02)$ \\
Airport enlargement & $0.04(0.03)$ & $0.06(0.03)^{*}$ & $0.06(0.03)^{* *}$ \\
HSR (in 10-20 km) & $0.08(0.008)^{* * *}$ & $0.06(0.01)^{* * *}$ & $0.06(0.01)^{* * *}$ \\
HSR (in 20-50 km) & $-0.02(0.04)$ & $-6 \mathrm{e}-3(0.04)$ & $-0.003(0.04)$ \\
Population & & $-7 \mathrm{e}-7(1 \mathrm{e}-6)$ & $-1 \mathrm{e}-6(1 \mathrm{e}-6)$ \\
Population squared & & $-1 \mathrm{e}-13(6 \mathrm{e}-13)$ & $1 \mathrm{e}-13(2 \mathrm{e}-13)$ \\
Hotel prices (regional) & & $9 \mathrm{e}-4(1 \mathrm{e}-3)$ & $0.001(0.001)$ \\
Flag carrier & Yes & $-0.004(0.003)$ & $-0.003(0.003)$ \\
Year effect & Yes & Yes & Yes \\
Monthly effect & $1.00(0.01)^{* * *}$ & $1.02(0.28)^{* * *}$ & Yes \\
Constant & 10,298 & $8,098(0.31)^{* * *}$ \\
\hline Observations & & Excluding & 8,578 \\
& All sample & municipalities & \\
Sample & & with HSR in all & All sample \\
& period & \\
Period & $2005-2015$ & $2005-2012$ & $2005-2012$ \\
$\mathrm{R}^{2}$ (within groups) & 0.12 & 0.13 & 0.12 \\
\hline
\end{tabular}

Note: ${ }^{* * *} 1 \%,{ }^{* *} 5 \%,{ }^{*} 10 \%$ significance test. Standard errors are shown in brackets.

Table 6. AVE effect on national visitors: panel data estimation (fixed effects)

\begin{tabular}{lccc}
\hline Explanatory variables & Model 1 & Model 2 & Model 3 \\
\hline HSR project & $0.01(0.04)$ & $0.02(0.05)$ & $0.03(0.05)$ \\
Airport enlargement & $-0.005(0.06)$ & $-0.01(0.06)$ & $0.008(0.06)$ \\
HSR (in 10-20 km) & $-0.21(0.02)^{* * *}$ & $-0.15(0.02)^{* * *}$ & $-0.16(0.02)^{* * *}$ \\
HSR (in 20-50 km) & $0.09(0.04)^{* *}$ & $0.05(0.06)$ & $0.04(0.05)$ \\
Population & & $-7 \mathrm{e}-6(2 \mathrm{e}-6)^{* *}$ & $-4 \mathrm{e}-6(2 \mathrm{e}-6)^{*}$ \\
Population squared & & $4 \mathrm{e}-12(1 \mathrm{e}-12)^{* * *}$ & $8 \mathrm{e}-13(3 \mathrm{e}-13)^{* *}$ \\
Hotel prices (regional) & & $2 \mathrm{e}-4(3 \mathrm{e}-3)$ & $3 \mathrm{e}-4(3 \mathrm{e}-3)$ \\
Flag carrier & & $-0.01(0.005)^{* *}$ & $-0.01(0.005)^{* *}$ \\
Year effect & Yes & Yes & Yes \\
Monthly effect & Yes & Yes & Yes \\
Constant & $8.88(0.05)^{* * *}$ & $9.58(0.43)^{* * *}$ & $9.58(0.45)^{* * *}$ \\
\hline Observations & 10,298 & 8,098 & 8,578 \\
& & Excluding & \\
Sample & All sample & municipalities & All sample \\
& & with HSR in all & \\
Period & period & $2005-2012$ \\
$\mathrm{R}^{2}$ (within groups) & $2005-2015$ & $2005-2012$ & 0.37 \\
\hline
\end{tabular}

Note: ${ }^{* * *} 1 \%,{ }^{* *} 5 \%,{ }^{*} 10 \%$ significance test. Standard errors are shown in brackets. 
Table 7. AVE effects on foreign visitors: panel data estimation (fixed effects)

\begin{tabular}{lccc}
\hline Explanatory variables & Model 1 & Model 2 & Model 3 \\
\hline HSR project & $0.02(0.04)$ & $0.07(0.04)$ & $0.09(0.04)^{* *}$ \\
Airport enlargement & $0.12(0.08)$ & $0.12(0.08)$ & $0.14(0.08)^{*}$ \\
HSR (in 10-20 km) & $-0.20(0.03)^{* * *}$ & $-0.09(0.04)^{* *}$ & $-0.14(0.04)^{* * *}$ \\
HSR (in 20-50 km) & $-0.17(0.06)^{* * *}$ & $-0.09(0.08)$ & $-0.12(0.07)^{*}$ \\
Population & & $-1 \mathrm{e}-5(5 \mathrm{e}-6)^{* *}$ & $-6 \mathrm{e}-6(4 \mathrm{e}-6)$ \\
Population squared & & $6 \mathrm{e}-12(3 \mathrm{e}-12)^{* *}$ & $1 \mathrm{e}-12(6 \mathrm{e}-13)^{* *}$ \\
Hotel prices (regional) & & $0.006(0.005)$ & $0.004(0.004)$ \\
Flag carrier & & $-0.03(0.006)^{* * *}$ & $-0.03(0.006)^{* * *}$ \\
Year effect & Yes & Yes & Yes \\
Monthly effect & Yes & Yes & Yes \\
Constant & $7.72(0.05)^{* * *}$ & $8.42(0.75)^{* * *}$ & $8.33(0.81)^{* * *}$ \\
\hline Observations & 10,296 & 8,096 & 8,576 \\
& & Excluding & \\
Sample & All sample & municipalities & All sample \\
& & with HSR in all & \\
Period & period & $2005-2012$ \\
$\mathrm{R}^{2}$ (Within groups) & $2005-2015$ & $2005-2012$ & 0.44 \\
\hline
\end{tabular}

Note: ${ }^{* * *} 1 \%,{ }^{* *} 5 \%,{ }^{*} 10 \%$ significance test. Standard errors are shown in brackets.

Table 8. AVE effects on the occupancy rate: panel data estimation (fixed effects)

\begin{tabular}{lccc}
\hline Explanatory variables & Model 1 & Model 2 & Model 3 \\
\hline HSR project & $-0.07(0.04)^{*}$ & $-0.07(0.04)^{*}$ & $-0.07(0.04)^{*}$ \\
Airport enlargement & $0.05(0.05)$ & $0.05(0.04)$ & $0.07(0.04)^{*}$ \\
HSR (in 10-20 km) & $0.04(0.01)^{* * *}$ & $0.04(0.01)^{* * *}$ & $0.05(0.01)^{* * *}$ \\
HSR (in 20-50 km) & $0.005(0.02)$ & $0.03(0.01)^{* *}$ & $0.03(0.01)^{* *}$ \\
Population & & $-3 e-6(1 \mathrm{e}-6)$ & $-3 \mathrm{e}-6(1 \mathrm{e}-6)^{* *}$ \\
Population squared & & $2 \mathrm{e}-12(1 \mathrm{e}-12)^{*}$ & $6 \mathrm{e}-13(2 \mathrm{e}-13)^{* *}$ \\
Hotel prices (regional) & & $0.009(0.001)^{* * *}$ & $0.009(0.001)^{* * *}$ \\
Flag carrier & & $-0.009(0.003)^{* * *}$ & $-0.01(0.004)^{* *}$ \\
Year effect & Yes & Yes & Yes \\
Monthly effect & Yes & Yes & Yes \\
Constant & $3.47(0.03)^{* * *}$ & $2.92(0.28)^{* * *}$ & $3.03(0.29)^{* * *}$ \\
\hline Observations & 10,293 & 8,081 & 8,561 \\
& & Excluding & \\
Sample & All sample & municipalities & All sample \\
Period & & with HSR in all & \\
$\mathrm{R}^{2}$ (within groups) & period & $2005-2012$ \\
\hline
\end{tabular}

Note: ${ }^{* * *} 1 \%,{ }^{* *} 5 \%,{ }^{*} 10 \%$ significance test. Standard errors are shown in brackets. 


\section{Conclusions}

This paper has tried to shed some light on the reality of the expected impact of highspeed rail in Spain, the country with the longest HSR network in Europe. We have particularly focused on the effects of new lines and stations on local tourism because it is one of the most claimed components of induced demand by HSR supporters and by representatives of the tourism industry. This study is also of interest for a country that receives more than 60 million visitors every year. In fact, after a careful consideration of the existing literature, we opted for an empirical analysis that intended to assess whether these effects were reality or just a myth, and whether their magnitude was relevant enough in comparison to the economic costs of this transport mode as compared to more (socially) affordable alternatives.

Building a database of tourism and transport data for Spanish municipalities in the 2005-2012 period, our microeconometric model combined two methodologies. Firstly, a difference-in-difference (DiD) approach that compared those municipalities that received HSR investments (i.e., nearby rail stations were built or enhanced) during this period, with those that did not. Our results show that the positive effects of HSR on the number of visitors, the number of nights spent at destination and/or the hotel occupancy rates are mostly restricted, at best, to larger cities, but in most cases they are minimal or even negative. To explore additional implications, we also estimated a panel model that simultaneously considered the effects on all the municipalities but again, the results were disappointing: no clear positive effects were found with respect to the tourism dependent variables and, in many cases, airport investments proved to be a better alternative.

Our results seem valid for the Spanish case but we should be cautious before generalising these results due to the specificities of its HSR network and transport policy. First, because the HSR fundamentally remains a domestic service, despite the recent connection to France that still offers poor demand volumes and only contributes marginally to the total volume of HSR passengers in Spain. In other countries international connections and shorter distances between main populated cities of different countries may help in promoting tourism by means of HSR services.

Second, because of the radial design of the network connecting Madrid with the rest of provinces in the periphery, regardless of transportation patterns and particularly regardless of touristic enclaves, most of them along the Mediterranean corridor which remains unconnected by HSR at speeds $>250 \mathrm{Km} / \mathrm{h}$. Moreover, in Spain interregional services are less developed than in France and other European countries, damaging the necessary interconnection and accessibility between radial corridors. No doubt this restricts the potential for tourism stimulation and for modal shift to rail.

Third, because low-cost airlines have dramatically developed domestic routes within Spain, competing in prices and frequencies with HSR and diverting tourists from rail to air and/or from places served by HSR to places not served by HSR. In this regards, recall that Spanish islands are massive tourist destinations not served by HSR.

Of course, the main conclusion of this paper is not that more airports should be built everywhere or that all high-speed rail developments are wrong projects from a social point of view. Even if investment costs cannot be recovered or can be only in the 
long-term, we support this transport mode for those cases where the social and economic justification sounds - at least - reasonable. This reasonability requires a detailed (and, preferably, public and opened to discussion) analysis of existing and prospect demand, a study of all the possible alternatives to tackle the exiting transport problem (if any), and a realistic consideration of the limited effects that HSR provides from the point of view of social and territorial cohesion. In the meantime, we would recommend a highly suspicious view on those projects mainly grounded on (expected) large induced demand effects (at the regional and local level). On this issue, it is possibly better to err on the side of caution, than to leave our grandchildren a bequest that they will be never able to pay.

These considerations are especially necessary for Spain because it is considered the country with the largest infrastructure oversupply, measured as the gap between transportation infrastructure capacity and its demand. As shown in Albalate et al. (2015b), the Spanish leadership in infrastructure supply is indisputable in all high capacity modes including motorways, high-speed rail, airports and ports. Yet, demand figures and demand growth has lagged far behind, especially in surface transportation modes, which require high investments to build a network. This damages any socioeconomic and financial analysis and it is the result of a transport policy unrelated to transportation or efficiency objectives, focused in spreading indiscriminately the public stock of infrastructure. This paper has focused in HSR as the main protagonist of this policy. Nonetheless, this analysis could be implemented to other modes of transportation with the same scepticism on its economic contribution, for instance, on tourism outcomes.

Although our results on HSR must not be directly generalised to other experiences, our empirical approach provides some additional insights on the determinants of local tourism. Structural changes in air transportation, the role of hotel prices and the size of municipalities all seem to play a significant role in explaining local tourism. Since their impacts should be closer or more homogeneous across countries these results could be more directly generalised or transferable. Our empirical approach could be also transferable and being implemented to estimate the impacts of HSR - o other modes of transportation - on tourism outcomes in countries with different transport policies and network designs of using a large international sample of municipalities. These are some ideas for further research that could clarify whether there is a Spanish singularity on the role of HSR on local tourism outcomes. 


\section{References}

Albalate, D. and G. Bel (2012): The economics and politics of high-speed rail. Lessons from experiences abroad. Rowman and Littlefield Publishers (Lexington Books), Lanham, MA.

Albalate, D. and X. Fageda (2016): "Evaluating HSR access on tourism: evidence from Spanish provinces and cities". Transportation Research Part A, 85, 174-185.

Albalate, D.; G. Bel and X. Fageda (2015a): "Competition and cooperation between high speed rail and air transportation services in Europe", Journal of Transport Geography, 42, 166-174.

Albalate, D.; G. Bel and X. Fageda (2015b) "When supply travels far beyond demand: causes of oversupply in Spain's transport infrastructure", Transport Policy 41, 80-89.

Bazin, S.; C. Beckerich and M. Delaplace (2006): "Analyse prospective des impacts de la Ligne à Grande Vitesse Est-européenne dans l'agglomération rémoise et en region Champagne-Ardenne", Report Final de recherché pour le Conseil Régional Champagne-Ardenne, Université de Reims Champagne-Ardenne.

Bazin, S.; C. Beckerich and M. Delaplace (2010): “Grande vitesse, activation des ressources spécifiques et développement du tourisme urbain: le cas de l'agglomération rémoise", Belgeo 1-2: 65-78.

Bazin, S.; C. Beckerich and M. Delaplace (2013): “Desserte TGV et villes petites et moyennes, Une illustration par le cas du tourisme à Arras, Auray, CharlevilleMézières et Saverne", Les Cahiers Scientifiques du Transport 63: 33-62.

Betancor, O. and G. Llobet (2015): "Contabilidad financiera y social de la alta Velocidad en España", Fundación de Estudios de Economía Aplicada, FEDEA. Available at www.fedea.net.

Bonnafous, A. (1987): "The Regional Impact of the TGV", Transportation, 14(2): 127137.

Cascetta, E.; A. Papola; F. Pagliara and V. Marzano (2011): “Analysis of mobility impacts of the high speed Rome-Naples rail link using within day dynamic mode service choice models", Journal of Transport Geography, 19(4): 635-643.

Cheng, Y-H. (2009): "High-speed rail in Taiwan: new experience and issues for future development", Transport Policy, 17(2): 51-63.

Chen, Z. and K. Haynes (2012): "Tourism industry and high speed rail, is there a linkage?: Evidence from China's high speed rail development". ASRDLF 2012 Conference Special Session on High Speed Rail, Tourism and Territories, July 911, 2012, Belfort, France.

Chen, Z. and K. Haynes (2015): "Impact of high-speed rail on international tourism demand in China", Applied Economic Letters, 22(1): 57-60.

Clavé, S., A. Gutiérrez and O. Saladi (2015): "High-speed rail services in a consolidated Catalan Mediterranean mass coastal destination: a causal approach", Workshop 
on High Speed Rail and the City: Tourism and Dynamics around stations, January 21-23, 2015, Paris.

Clever, R. and M. Hansen (2008): "Interaction of air and high-speed rail in Japan", Transportation Research Record: Journal of the Transportation Research Board, 2043: 1-12.

Clewlow, R.R.L., J.M. Sussman and H. Balakrishnan (2012): "Interaction of high-speed rail and aviation: exploring air-rail connectivity", Transportation Research Record: Journal of the Transportation Research Board, 2266(1): 1-10.

COM - European Commission (1996): "Interaction between high-speed and air passenger transport". Interim Report on the Action COST 318, April. Brussels.

Coronado, J.M., Garmendia, M., Moyano, A. and Ureña, J.M. (2013): “Assessing Spanish HSR network utility for same-day tourism", Recherche Transport Secutiré, 2013(03), 161-175.

Delaplace, M. (2012): “TGV, développement local et taille des villes. Une analyse en termes d'innovation de services, Revue d'économie régionale et urbaine, 2: 265-292.

Delaplace, M. and J. Perrin (2013): "Multiplication des dessertes TGV et Tourismes urbains et d'affaires, Regards croisés sur la Province et l'lle de France", Recherche Transport et Sécurité, 29:177-191.

Delaplace, M.; F. Pagliara; J. Perrin and S. Mermet (2014): "Can high-speed rail foster the choice of destination for tourism purpose?" EWGT2013 - 16th Meeting of the EURO Working Group on Transportation, Procedia - Social and Behavioral Sciences, 111: $166-175$.

de Rus, G. (2011): "The BCA of HSR: Should the government invest in high speed rail infrastructure?", The Journal of Benefit-Cost Analysis, 2(1): 1-28

de Rus, G. and V. Inglada (1993): “Análisis coste-beneficio del tren de alta velocidad en España", Economía Aplicada, 3: 27-48.

de Rus, G. and V. Inglada (1997): "Cost-benefit analysis of the high-speed train in Spain", The Annals of Regional Science, 31: 175-188.

de Rus, G. and G. Nombela (2007): "Is investment in high-speed rail socially profitable?", Journal of Transport Economics and Policy, 41(1): 3-23.

Dobruszkes, F. (2011): "High-speed rail and air transport competition in Western Europe: a supply-oriented perspective", Transport Policy, 18: 870-879.

Dobruszkes, F. and V. Mondou (2013): “Aviation liberalization as a means to promote international tourism: the EU-Morocco case", Journal of Air Transport Management, 29:23-34.

Dobruszkes, F.; C. Dehon and M. Givoni (2014): “Does European high-speed rail affect the current level of air services? An EU-wide analysis", Transportation Research Part A, 69: 461-475.

Edwards, N. (2012): High-speed rail benefits that add up, Report for the Australian Greens. Melbourne. 
Ellwanger,G. and M. Wilckens (1993): "Hochgeschwindigkeitsverkehr gewinnt an Fahrt" (High-speed traffic booms). Internationales Verkehrswesen, 45 (5): 284290.

Feliu, J. (2012): "High-Speed Rail in European Medium-Sized Cities: Stakeholders and Urban Development", Journal of Urban Planning and Development, 138: 293302.

FRONTUR (2015): “Movimientos turísticos en frontera" (Tourism at borders). Instituto de Estudios Turísticos. Online available at www.iet.tourspain.es.

Fu, X.; A. Zhang and Z. Lei (2012): “Will China's airline industry survive the entry of high-speed rail?", Research in Transport Economics, 35(1): 13-25.

Givoni, M. and D. Banister (2006): "Airline and railway integration", Transport Policy, 13: 386-397.

Givoni, M. and F. Dobruszkes (2013): "A review of ex-post evidence for mode substitution and induced demand following the introduction of high-speed rail", Transport Reviews, 33(6): 720-742.

Haynes, K. (1997): "Labour markets and regional transportation improvements. The case of high-speed trains: an introduction and review", The Annals of Regional Science, 31 (1): 57-76.

Hernández, A. and J.L. Jiménez (2014): "Does high-speed rail generate spillovers on local budgets", Transport Policy, 35: 211-219.

Hickman, R., Givoni, M., Bonilla, D., Banister, D. (2015) Handbook of transport and development. Edward Elgar.: Cheltenham, UK. p. 736

Jiménez, J.L. and O. Betancor (2012): "When trains go faster than planes: the strategic reaction of airlines in Spain", Transport Policy, 23: 34-41.

Kappes, J.W. and R. Merkert (2013): "Barriers to entry into European aviation markets revisited: a review and analysis of managerial perceptions", Transportation Research Part E, 57: 58-69.

Klein, O. (1997): "Le TGV-Atlantique et les évolutions de la mobilité: entre crise et concurrence", Les Cahiers Scientifiques des Transports, 32: 57-83.

Klein, O. and G. Claisse (1997): "Le TGV-Atlantique: entre récession et cencurrence. Evolution de la mobilité et mise en service du TGV-Atlantique: analyse des enquêtes réalisées en septiembre 1989 et septiembre 1993". Lyon. Laboratoire d'Economie des Transports.

Lee, J.-K.; K.E. Yoo and S.-Y. Jung (2012): "A study on the effect of high-speed railway launch to the air passengers' mode choice behaviour", 16th ATRS World Conference, Tainan, Taiwan, June 2012.

Leiper, N. (1990): "Tourist Attraction Systems", Annals of Tourism Research, 17(3): 367-384.

Martín, J.C. and G. Nombela (2008): "Microeconomic impacts of investments in high speed trains in Spain", The Annals of Regional Science, 41:715-733. 
Masson, S. and R. Petiot (2009): "Can high-speed rail reinforce tourism attractiveness? The case of the high-speed rail between Perpignan (France) and Barcelona (Spain)", Technovation, 29(9): 611-617.

Murakami, J. and R. Cervero (2012): "High-speed rail and economic development: business agglomerations and policy implications", UC Berkeley, University of California Transportation Centre (UCTC).

Okabe, S. (1979): "Impact of the Sanyo Shinkansen on Local Communities", in Proceedings of the International Institute for Applied Systems Analysis Conference, June 27-30, 1977), A. Straszak, and R. Tuch (eds.): 105-129.

Ortuño-Padilla, A.; D. Bautista-Rodríguez; P. Fernández-Aracil; G. Fernández-Morote and J.C. Sánchez-Galiano (2015): "HSR passengers profile in sun and beach tourism destinations: the case of Alicante (Spain)". Workshop on High Speed Rail and the City: Tourism and Dynamics around stations, January 21-23, 2015, Paris.

Pagliara, F.; J.M. Vassallo and C. Román (2012): "High-speed rail vs. air transportation. A case study of Madrid-Barcelona, Spain", Transportation Research Record, 2289, 10-17.

Pagliara, F.; A. La Pietra; J. Gómez and J.M. Vassallo (2015): "High-speed rail and the tourism market: evidence from the Madrid case study", Transport Policy, 37: 187-194.

Rey, B.; R. Myro and A. Galera (2011): "Effect of low-cost airlines on tourism in Spain. A dynamic panel data model", Journal of Air Transport Management, 17: 163167.

Román, C.; R. Espino and J.C. Martín (2007): "Competition of high-speed train with air transport: the case of Madrid-Barcelona", Journal of Air Transport Management, 13: 277-284.

SEEDA, South East England Development Agency (2008). HST Impact Study, Final report for the European Commission. Available at http://www.hstimpactstudy.net/.

Shen, Y.; de Abreu and Silva; J. and M. Martínez (2014): "HSR Station Location Choice and its Local Land Use Impacts on Small Cities: A Case Study of Aveiro, Portugal", Procedia - Social and Behavioral Sciences. Volume 111, 5 February 2014, Pages 470-479. Transportation: Can we do more with less resources? 16th Meeting of the Euro Working Group on Transportation - Porto 2013

Suh, S.; Y. Keun-yul and K. Jeon Hyun (2005): "Effects of Korean Train Express (KTX) operation on the national transport system", Proceedings of the Eastern Asia Society for Transportation Studies, 5: 175-189.

Taniguchi, M. (1992): "High Speed Rail in Japan: A Review and Evaluation of the Shinkansen Train". University of California Working Paper UCTC, no. 103.

UNWTO (2015): World Tourism Organization. Online Statistics. Available at www.unwto.org

Van den Berg, Leo and P. Pol (1998): The European high-speed train network and urban development. Aldershot: Ashgate. 
Vickerman, R. (1997): "High-speed rail in Europe: Experience and issues for future development", The Annals of Regional Science, 31: 21-38.

Wang X.; S. Huang; T. Zou and H. Yan (2012): "Effects of the high speed rail network on China's regional tourism development", Tourism Management Perspectives, 1: 34-38.

Wu, J. (2013): “The financial and economic assessment of China's high-speed rail investments: a preliminary analysis". Discussion Paper, International Transport Forum 2013, Paris.

Zhang, Q.; H. Yang; Q. Wang; A. Zhang (2014): "Market power and its determinants in the Chinese airline industry", Transportation Research Part A: Policy and Practice, 64: 1-13. 